\title{
STUDY OF FUNCTIONAL OUTCOME OF CONVERSION TOTAL HIP ARTHROPLASTY
}

\author{
R. Sahaya Jose 1 \\ ${ }^{1}$ Assistant Professor, Department of Orthopaedics, Sree Mookambika Institute of Medical Sciences.
}

ABSTRACT: Conversion Total Hip Arthroplasty is a Total Hip Arthroplasty done for failed internal fixation or failed hemiarthroplasty done for fractures of the proximal femur. The Conversion Total Hip Arthroplasty (THA) has been reported to be associated with very high rates of Intra and post-operative complications. Conversion THA is a technically challenging procedure and the overall clinical outcome is generally less satisfactory than primary THA. Risk factors include removal of the failed components, deficient host bone stock and re insertion of new components. In our study we have evaluated the short term functional outcome of patients who underwent conversion total hip arthroplasty using Harris Hip Score. Ours is both prospective and retrospective study of 22 patients of conversion THA done from October 2008 to October 2015. Our study includes cases of failed hemiarthroplasty converted to THA and failed internal fixation of proximal femoral fractures converted to THA. Our results indicate that conversion total hip arthroplasty is an excellent treatment strategy for symptomatic failed hemiarthroplasty and failed internal fixation for proximal femoral fractures in terms of pain relief and restoration of function and mobility as near as possible to the pre-injury level. The results of our study are rewarding in term of improving patient's quality of life as evidenced by pre-operative and post-operative Harris Hip Score. We have come to a conclusion that conversion total hip arthroplasty done following failure of unipolar/bipolar hemiarthroplasty gave similar results in our study like that of the conversion total hip arthroplasty done following failed internal fixation for proximal femoral fractures. Our overall mean Harris hip score preoperatively 37.45 was increased to post-operatively 82.59 .

KEYWORDS: Total Hip Arthroplasty (THA), Harris Hip Score (HHS), Hemiarthroplasty, Failed Internal Fixation.

HOW TO CITE THIS ARTICLE: R. Sahaya Jose. "Study of Functional Outcome of Conversion Total Hip Arthroplasty". Journal of Evolution of Medical and Dental Sciences 2015; Vol. 4, Issue 92, November 16; Page: 15722-15727,

DOI: $10.14260 /$ jemds/2015/2268.

INTRODUCTION: Conversion total hip arthroplasty is a total hip arthroplasty done for failed internal fixation or failed hemiarthroplasty done for fractures of the proximal femur. The primary goals of conversion total hip arthroplasty are long term reduction of pain and improvement of function after failed primary surgeries. Fulfillment of these goals requires long term stable mechanical fixation of the implanted components acceptable wear rates of the articulating surface minimization of osteolysis and avoidance of infection. Conversion total hip arthroplasty also demands additional attention to potential problems such as removal of failed components and cement, deficient host bone stock and reinsertion of new components.

Conversion total hip arthroplasty is more complicated than primary Total hip replacement and has become a focus for the arthroplasty surgeons. It demands more of a surgeon than the hospital. The key for successful conversion THA is preparation for multiple possibilities and clear plans about what to do for each possibility. The goals of conversion total hip replacement surgery are to improve mobility by relieving pain and to improve the function of the hip joint. Total hip arthroplasty could either be cemented or uncemented.

In our center both cemented and uncemented conversion total hip replacements are done and we have decided to evaluate the short term functional outcome of

Financial or Other, Competing Interest: None.

Submission16-10-2015, Peer Review 17-10-2015,

Acceptance 28-10-2015, Published 13-11-2015.

Corresponding Author:

Dr. R. Sahaye Jose,

119-Jose Bhavan, Puthukudieruppu, Nagercoil-629001,

Kanyakumari, Tamilnadu.

E-mail:drjose07@yahoo.co.in

DOI:10.14260/jemds/2015/2268. conversion total hip arthroplasty with a mean follow up of 31.9 months using Harris Hip Score.

AIMS OF THE STUDY: To evaluate the functional outcome of patients who underwent Conversion Total Hip Arthroplasty.

MATERIALS AND METHODS: The present study includes 22 patients of conversion THA done from October 2008 to October 2015 with follow up of 12 months to 84 months, with a mean follow up of 31.9 months. It is a prospective and retrospective study. Our study has 11 prospective cases and 11 retrospective cases.

Out of 22 cases, 14 cases were cases converted from hemi arthroplasty to THA and 8 cases were cases in which THA was done for failed internal fixation of proximal femoral fractures. For all the cases we used posterior approach. ${ }^{1}$ Out of 22 cases, 14 cases were cemented and 8 cases were uncemented THA. Our study does not have any bilateral hip cases. Out of 22 THA's, 11 were right hips and the other 11 were left hips. The age group of patients ranges from 33 to 80 years with a mean of 60 years. Indications for conversion THA are pain and functional disability due to aseptic loosening, erosion of acetabulum, subsidence, and non-union with implant failure.

FOLLOW-UP: Prospective patients were reviewed regularly and at 6 weeks, 3 months, 6 months, 1 year and then yearly follow up. Retrospective study patients were reviewed every yearly. Patients were assessed radiologically and clinically using Harris Hip Score.

\section{Inclusion Criteria:}

\section{FAILED HEMIARTHROPLASTY:}

- Austin Moore.

- Thompson.

- Bipolar Hemiarthroplasty. 
FAILED INTERNAL FIXATION OF PROXIMAL FEMORAL FRACTURES:

- Cancellous hip screw.

- Dynamic hip screw.

- Angle Blade plate.

Exclusion Criteria:

- Infection following hemi/bipolar hemiarthroplasty.

- Infected internal fixation for proximal femoral fractures.

- Pathological femur fractures.

- Primary total hip arthroplasty.

RESULTS: The 22 hips were evaluated clinically. Clinical evaluation using Harris hip score revealed the following:

DISCUSSION: Clinical evaluation was done pre-operatively and post-operatively at regular intervals using Harris Hip Score, which takes into account pain, limp, support. Walking distance, stair climbing, range of motion and deformity.

Cossey and Goodwin [2002].2 have shown that conversion total hip replacement for symptomatic failed hemiarthroplasty gave the patient a pain free and functionally acceptable lifestyle.

The goal of conversion total hip arthroplasty is to return the patients to the pre injury functional state as rapidly as possible. Pain following hemi arthroplasty is usually due to one of the two pathological processes: articular cartilage degeneration in the acetabulam or loosening of the prosthesis. These pathological processes are exacerbated by many factors including incongruence between the femoral head and the acetabulam, excessive neck length, impaction at the time of injury, cementation of the prosthesis, physiologically young active patients and shear forces between the prosthesis and the cartilage.

Mohamed and Sharaf [2004].6 et al observed that articulation with hemiarthroplasy prosthesis for only 5 years may lead to lesions of the acetabular cartilage that are sufficiently severe to limit activity. Dalldorf et al [1995]. ${ }^{7}$ also observed that acetabular cartilage will degenerate in a similar fashion following hemiarthroplasty.

The bone quality usually is poor as a result of preexisting osteoporosis which further decreases as a result of disuse after the failure of internal fixation. The greater trochanter either is not solidly healed or can be fragmented again during hip arthroplasty, thus affecting abduction function, which leads to an increased dislocation rate and can adversely affect ambulation.

The reported failure rates are due to device penetration, non-union and mal-union causing varus deformity. In displaced intracapsular hip fractures a fifth of the patients initially treated with reduction and internal fixation required conversion total hip arthroplasty within 2 years usually because of nonunion or avascular necrosis

Parker et al. ${ }^{8}$ also showed a reoperation rate of $40 \%$ for displaced femoral neck fractures treated with internal fixation. Problem with THA after failed internal fixation devices is due to frequently broken screws which must be removed from the femur.

The surgeon must dissect through the old scars to expose the internal fixation device which also caused increased blood loss.

When hip arthroplasty has been used to treat failed internal fixation of intertrochantric fractures most surgeons used a long stem femoral component so as to bypass the stress riser effect of the most distal screw hold

Winemaker et al [2006]. ${ }^{9}$ reported deep infection rate of $3.8 \%$, periprosthetic fracture rate of $6.2 \%$ dislocation rate of $11.4 \%$ early implant failure rate of $1.5 \%$ and reoperation rate of $10.9 \%$. In our study we have 5 cases $(23 \%)$ of periprosthetic fracture and all were intraoperative for 1 case we did dynamic condylar screw for periprosthetic fracture and for all the other 4 cases, we used cerclage wires and we used a long stem THA. Periprosthetic fracture is the most commonly encountered complication in our series of conversion THA.

In our study we had 2 patients (9\%) with limb length discrepancy i.e. lengthening- $1 \mathrm{~cm}$ and $1.5 \mathrm{~cm}$ respectively.Heterotopic bone when present was grades according to the classification of Brooker et al. ${ }^{10}$ In our series we have 1 hip (4.5\%) which developed heterotopic ossification,type II ossification.

In our study, there was one case with poor outcome; probably due to ipsilateral osteoarthrosis of knee. Hence, the patient's functional outcome was poor and radiologically the stem position was varus.

\section{CONCLUSION:}

- We have done a short term follow up of Conversion Total Hip Arthroplasty. From our study we have arrived at the following conclusion:

- Conversion of hemiarthroplasty to THA is a challenging surgery due to general condition of those elderly patients and due to the surgical techniques used to pass the operation safely. Otherwise it may lead to complications such as periprosthetic fractures.

- Harris Hip Score is an excellent scoring system for assessing the functional outcome of conversion total hip arthroplasty. We have $73 \%$ of excellent and good results and fair results of $23 \%$.

- The results of our study are rewarding in term of improving patients' quality of life as evidenced by preop and post-op Harris hip score.

- Conversion total hip arthroplasty is an excellent treatment strategy for symptomatic failed hemiarthroplasty and failed internal fixation for proximal femoral fractures in terms of pain relief and restoration of function and mobility as near as possible to the pre-injury level.

- The conversion arthroplasty done following failure of unipolar/bipolar hemiarthroplasty gave similar results in our study like that of the conversion total hip arthroplasty done following failed internal fixation for proximal femoral fractures.

- Conversion THA following cancellous screws gave better results than conversion following DHS/angle blade plate.

- Periprosthetic fracture is the most commonly encountered complication in conversion total hip arthroplasty.

- Our overall mean Harris hip score pre-operatively 37.45 was increased to post-operatively 82.59. 


\section{BIBLIOGRAPHY:}

1. S Terry Canale, James H.Beaty. Campbell's operative orthopaedics.12 ${ }^{\text {th }}$ ed.Mosby Elsevier;2013.

2. Cossey A, Goodwin M., failure of Austin Moore Hemi: THR as a treatment strategy injury 2002; 33: $19-21$.

3. Hammed, A Abdel - AAL described about the functional outcome of convertion THR in Egyptian population Acta Orthopaedia Belgica Vol 72-5-2006.

4. Total hip arthroplasty following failed fixation of proximal hip fractures, Shekar Srivastav, Vivek Mittal, Shekar Agarwal, Delhi institute of trauma and orthopaedics - 2005.

5. Amstutz R, Smith R, THR following failed femoral Hemiarthroplasty JBJS 1979 61A: 1161- 1166.

6. Amr Mohamed Abdelhady Sharaf. Total hip replacement after failed hip hemiarthroplasty.Pan Arab J.Orth.Trauma.2004 July;8(2):163-166.

\section{FUNCTIONAL RESULTS:}

\begin{tabular}{|c|c|c|}
\hline EXCELLENT & 4 & $18 \%$ \\
\hline GOOD & 12 & $55 \%$ \\
\hline FAIR & 5 & $23 \%$ \\
\hline POOR & 1 & $4 \%$ \\
\hline
\end{tabular}

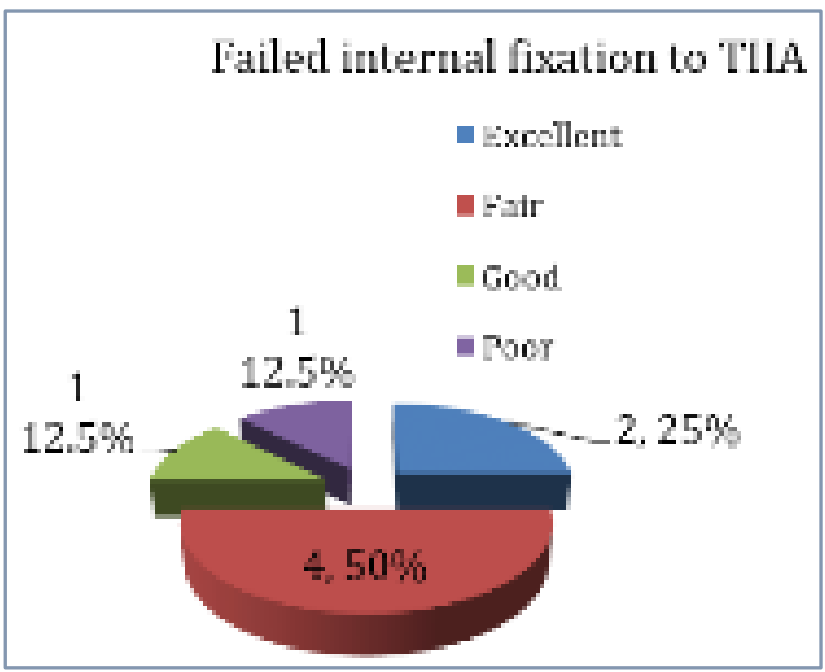

Functional outcome of Hemiarthroplasty to THA:

We had 14 cases of failed hemiarthroplasty converted to THA. Clinical evaluation using Harris hip score revealed the following.

\begin{tabular}{|c|c|c|}
\hline EXCELLENT & 2 & $14 \%$ \\
\hline GOOD & 11 & $79 \%$ \\
\hline FAIR & 1 & $7 \%$ \\
\hline POOR & - & - \\
\hline
\end{tabular}

7. Dalldorf PG, Banas MP, Hicks DG; Rate of degeneration of human acetabular cartilage after hemiarthroplasty. JBJS 1995; 77-A; 877-882.

8. Parker MJ, Khan, Crawford J, pryor GA, hemiarthroplasty versus fixation for displaced intracapsular hip fractures in elderly.JBJS.Br 2002; 84; 1150-5.

9. Shorterm outcome of THR after complications of open reduction internal fixation for hip fractures - Journal of arthroplasty Vol. 21, No.5 2006, Mitchel Winemaker, Patrick, Danielle, Sarkis, Justin.

10. Brooker AF, Bowermann RA, Railey LH, ectopic ossification following THR, Incidence and classification JBJS 55A:1629-1632, 1973.

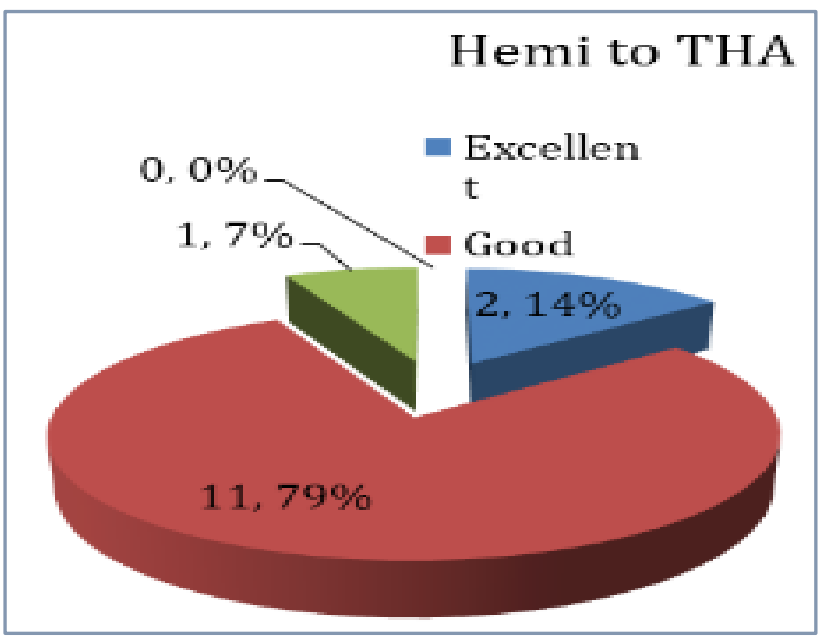

Functional outcome of Failed Internal Fixation to THA:

We had 8 cases of failed internal fixation of proximal femoral fractures converted to THR.

Clinical evaluation using Harris hip score revealed the following:

\begin{tabular}{|c|c|c|}
\hline EXCELLENT & 2 & $25 \%$ \\
\hline GOOD & 1 & $12.5 \%$ \\
\hline FAIR & 4 & $50 \%$ \\
\hline POOR & 1 & $12.5 \%$ \\
\hline
\end{tabular}

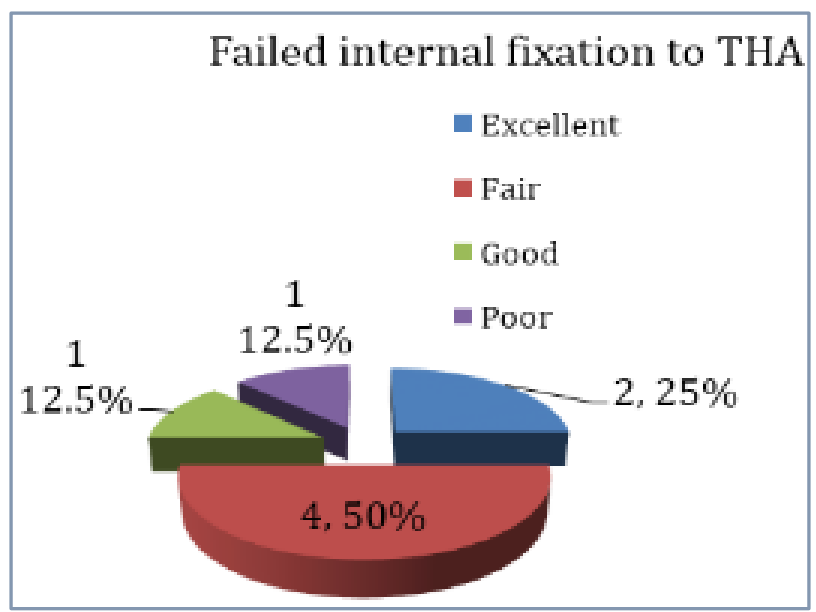




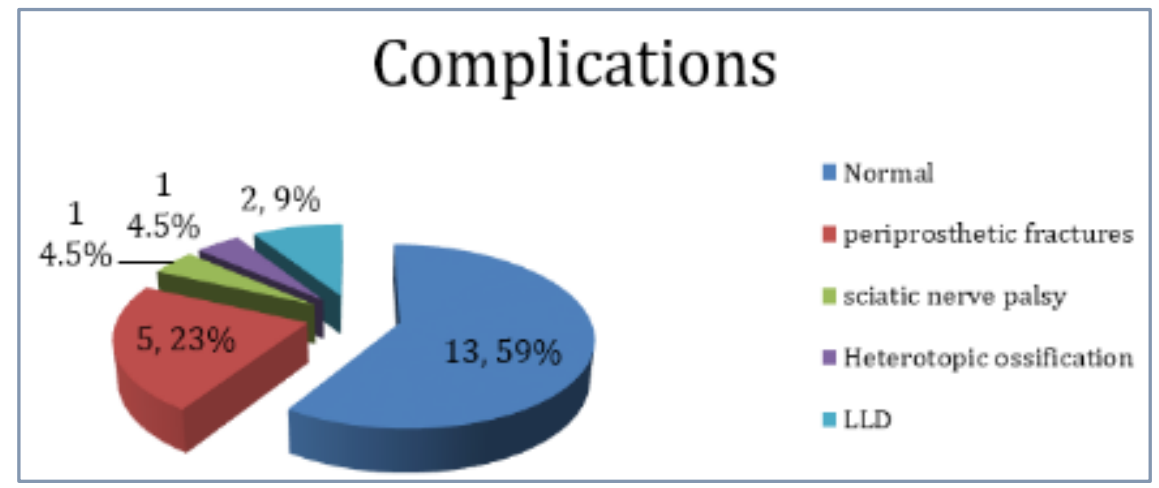

\section{COMPLICATIONS:}

- Heterotopic Ossification $\rightarrow 1$

- Limb length discrepency $\rightarrow 2$

- Sciatic nerve palsy $\rightarrow 1$

- Periprosthetic fracture $\rightarrow 5$

- In our study, there was no wound gaping/infection/loosening of implant/dislocation/ embolism.

Comparison of Pre-op and latest Harris hip score:

Hemiarthroplasty $\rightarrow$ THA

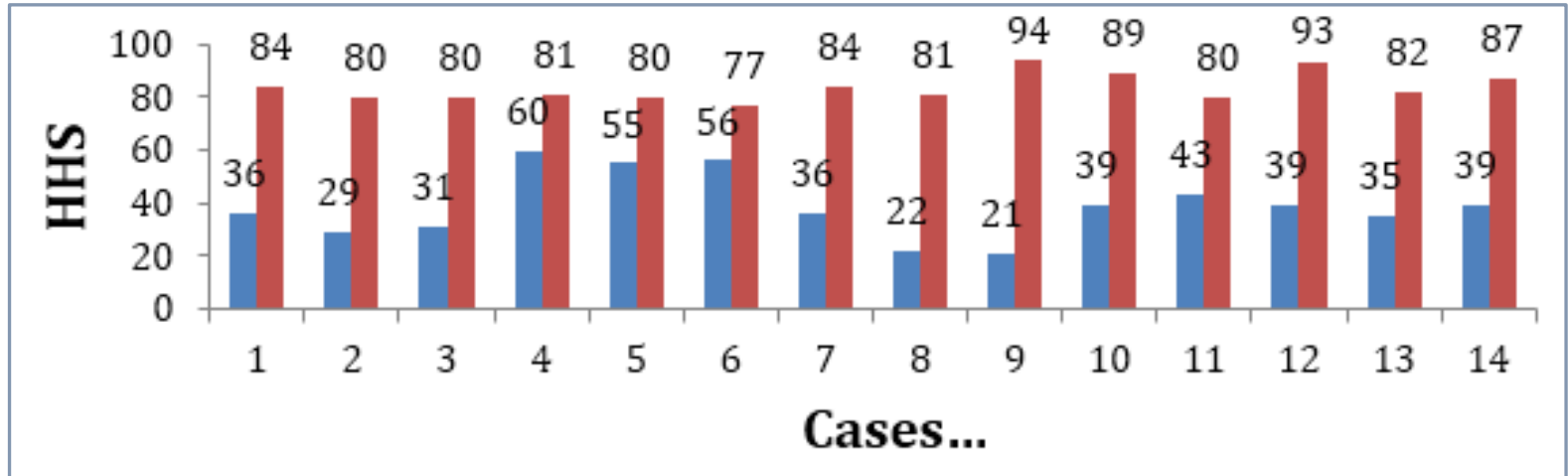

Failed Internal Fixation $\rightarrow$ THA

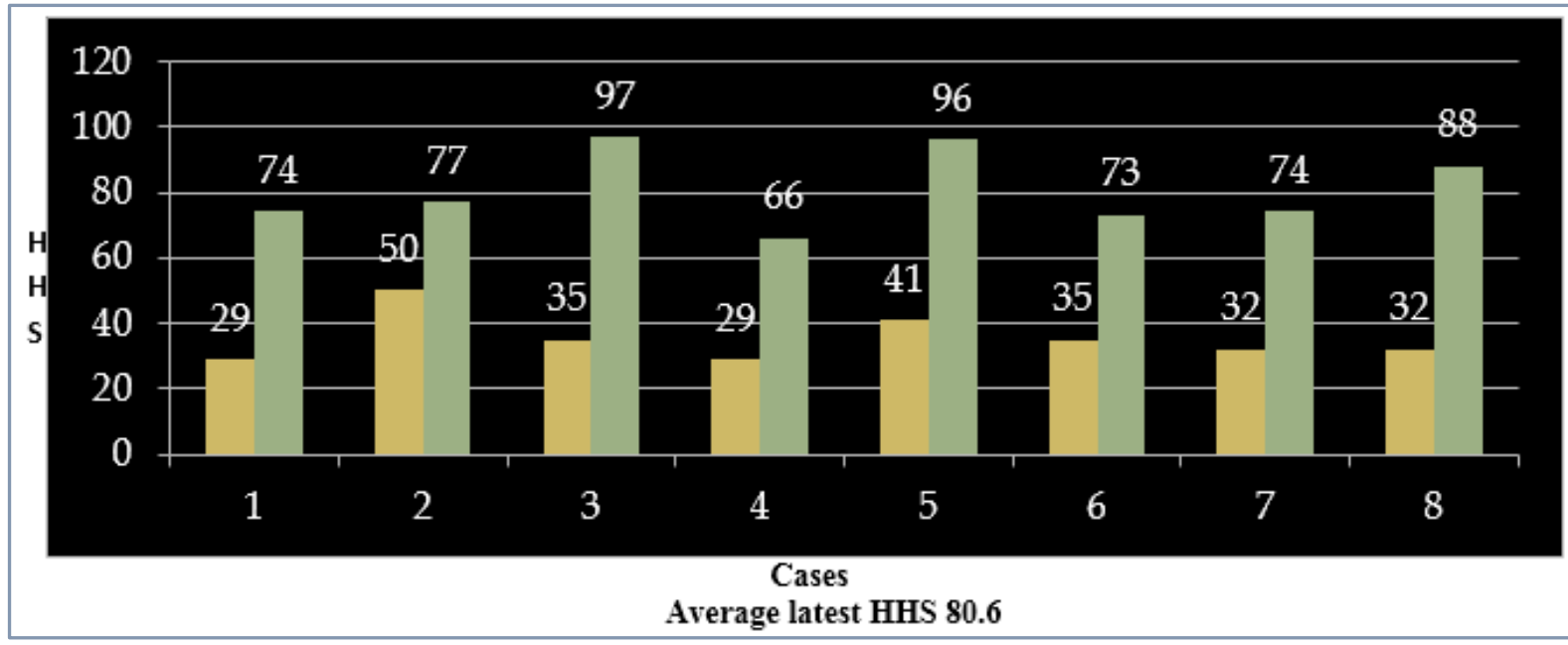

\begin{tabular}{|c|c|c|c|}
\hline & Mean pre-op HHS & Mean latest HHS & Mean Difference in HHS \\
\hline Hemiarthroplasty $\rightarrow$ THA & 38.6 & 83.7 & 45.1 \\
\hline Failed internal fixation $\rightarrow$ THA & 35.3 & 80.6 & 45.3 \\
\hline
\end{tabular}


Case 1- Excellent Result:

Pre op HHS - 21.

Latest HHS - 94.
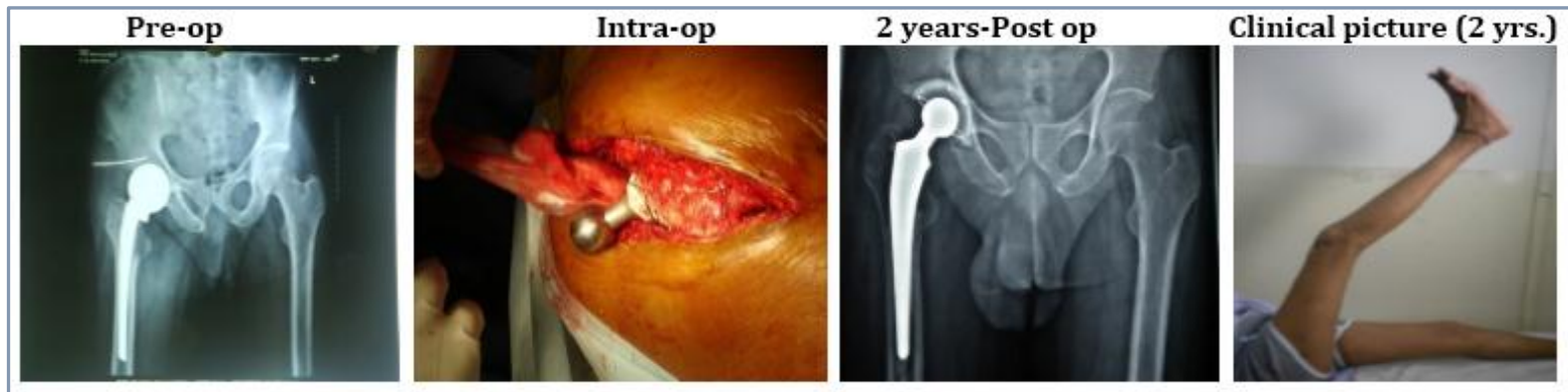

Case 2 - Good result:

Pre op HHS- 39.

Latest HHS- 89.

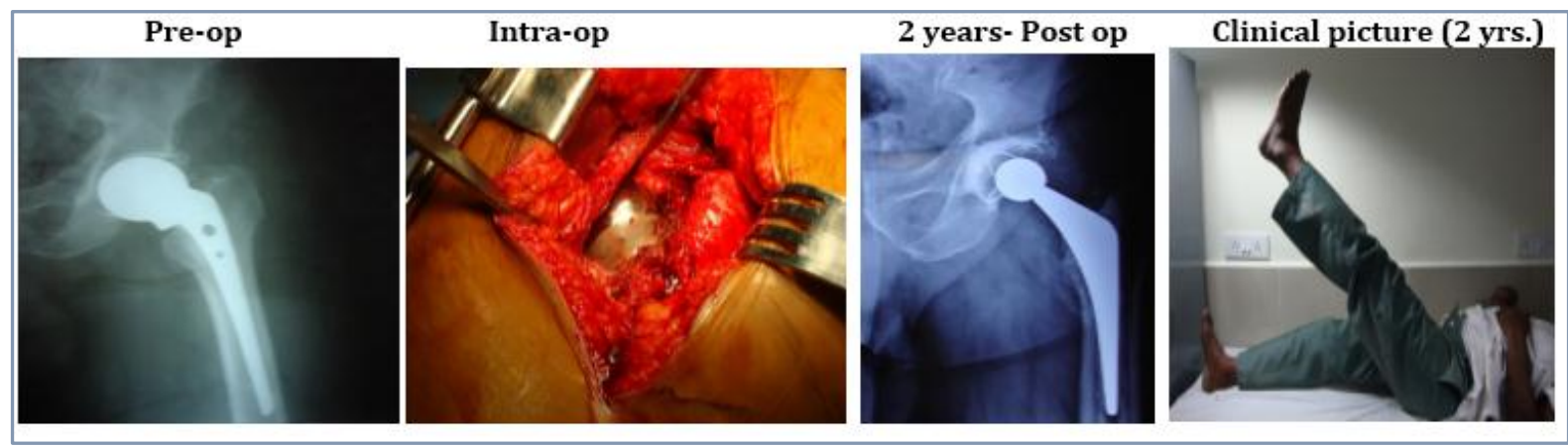

Case 3 - Poor outcome

Pre op HHS-29.

Latest HHS-66.

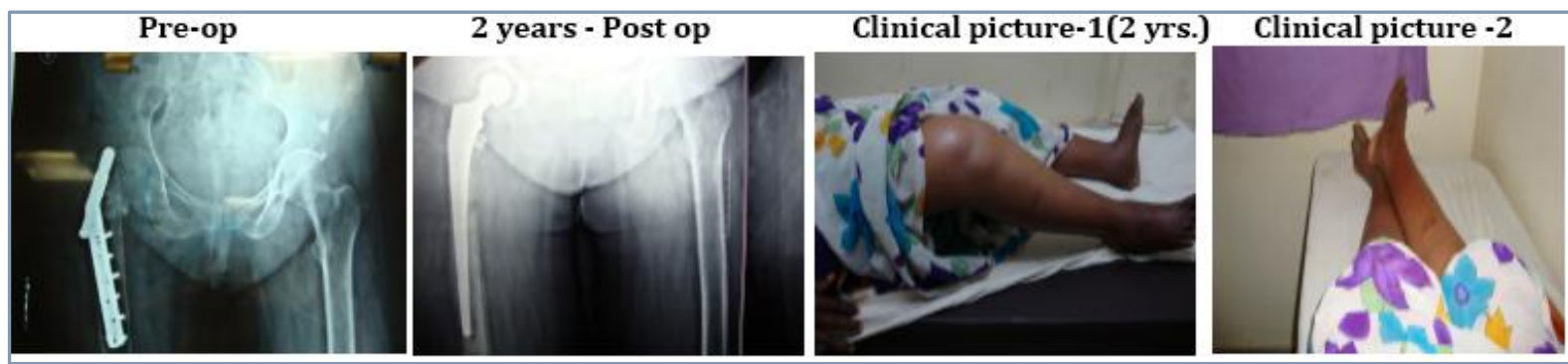

Complications:

- Peri-prosthetic fracture

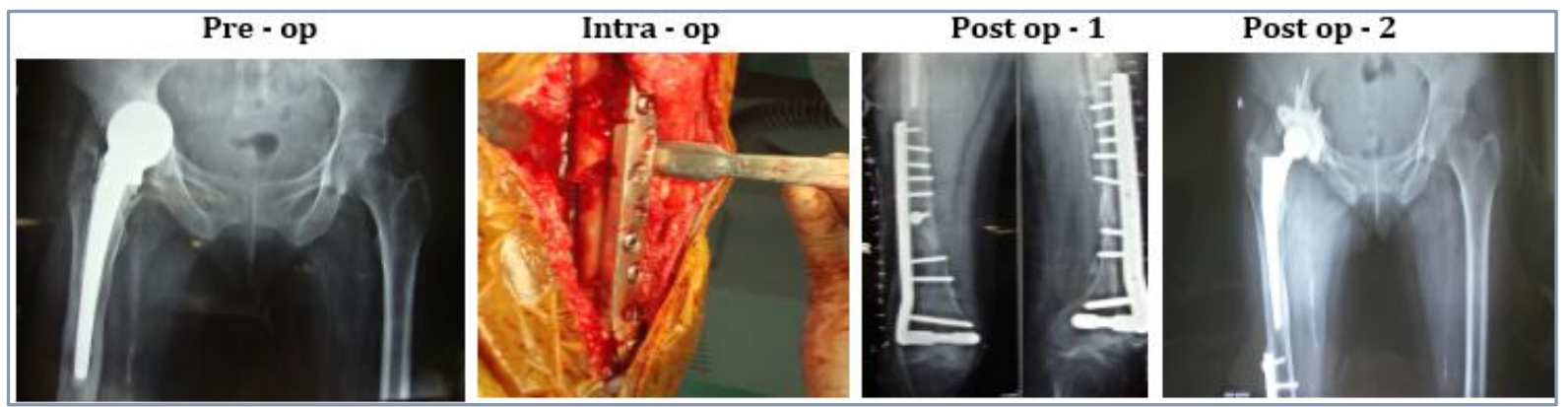




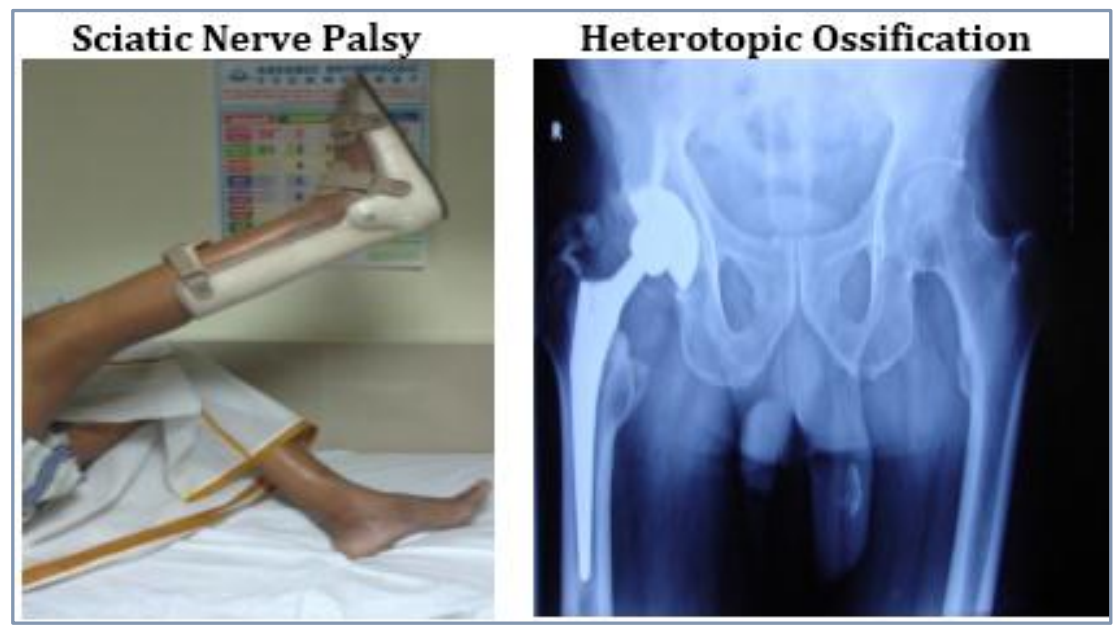

\section{Comparison:}

\begin{tabular}{|c|c|c|}
\hline & Hammad et al. $^{\mathbf{3}}$ & Our Study \\
\hline Mean Preop HHS & 33.95 & 37.45 \\
\hline Mean Latest HHS & 86.60 & 82.59 \\
\hline
\end{tabular}

In Hammad et al's. ${ }^{3}$ study the Mean Preop HHS of 33.95 was elevated to 86.60, whereas in our study the Mean Preop HHS of 37.45 was elevated to 82.59 , which is comparable.

\section{Comparison - Hemiarthroplasty to THA}

\begin{tabular}{|c|c|c|}
\hline Functional result & Hammad et al. $^{\mathbf{3}}$ & Our Study \\
\hline Excellent & $19.1 \%$ & $14 \%$ \\
\hline Good & $74.5 \%$ & $79 \%$ \\
\hline Fair & $4.3 \%$ & $7 \%$ \\
\hline Poor & $2.1 \%$ & $0 \%$ \\
\hline
\end{tabular}

In Hammad et al's. ${ }^{3}$ study, the functional outcomes were comparable to those achieved in our study.
Comparison-Failed Internal Fixation of proximal femoral fractures to THA

\begin{tabular}{|c|c|c|}
\hline Functional result & Mittal et al. ${ }^{4}$ & Our Study \\
\hline Excellent & $27 \%$ & $25 \%$ \\
\hline Good & $53 \%$ & $50 \%$ \\
\hline Fair & $8 \%$ & $12 \%$ \\
\hline Poor & $12 \%$ & $13 \%$ \\
\hline
\end{tabular}

In Mittal et al's. ${ }^{4}$ series, there were no evidence of infection as a cause of failure of internal fixation and all the surgeries were performed in single stage, so as our study.

While analyzing the results after conversion THR following failed cancellous screws and following failed DHS/angle blade plate, we found that conversion following failed cancellous screws gave better results.

Following failure of DHS/angle blade plate fixation, there could be loss of calcar as well as inadequate abductor mechanism, which will have negative influence on the final outcome.

\begin{tabular}{|c|c|c|c|}
\hline Complications & Amstutz and Smith. 5 & Cossey and Goodwin. ${ }^{3}$ & Our study \\
\hline Intraop femoral fractures & 5 & - & 5 \\
\hline Perforation of medial cortex with stem protrusion & 2 & - & 0 \\
\hline Instability & 2 & - & 0 \\
\hline Infection & 2 & 2 & 0 \\
\hline DVT & 3 & - & 0 \\
\hline Progressive loosening & 6 & 0 & 0 \\
\hline Dislocation & - & 0 & 0 \\
\hline Sciatic nerve palsy & - & - & 1 \\
\hline Heterotopic ossification & - & - & 1 \\
\hline LLD & - & - & 2 \\
\hline Mortality & - & 3 & 0 \\
\hline
\end{tabular}

